\title{
Asymmetric volatility spillovers between UK regional worker flows and vacancies
}

\author{
Deborah Gefang \\ Department of Economics \\ University of Leicester \\ Leicester LE1 7RH \\ United Kingdom
}

\author{
Geraint Johnes* \\ Department of Economics \\ Lancaster University Management School \\ Lancaster LA1 4YX \\ United Kingdom
}

February 2017

\begin{abstract}
This paper investigates volatility spillovers between UK regional job finding, job separation and vacancy rates. Employing a large Bayesian logistic smooth transition vector autoregression (VAR) model, we find high volatility spillovers between UK regional labour markets. Analyses of net spillovers show that, in general, shocks to job separation rates tend to spread into job finding and vacancy rates, while vacancy rates are usually at the receiving end of shocks transmitted from the job separations and job findings. To shed further light on the shock propagation mechanism, we also look into more detailed matters such as the differences in spillovers between regions within the same regime, and that of the same region but in different regimes.
\end{abstract}

JEL: C11, C32, C51, J63.

*Corresponding author

\section{Introduction}

The spatial dynamics of labour market variables in the UK regions has, at various times, been a topic of significant interest to economists. This is so especially in the wake of recessions, including those of the 1980s and 1990s. We aim, in this paper, to investigate such dynamics by analysing the way 
in which shocks - to unemployment inflows and outflows and also vacancies - propagate across labour market variables and regions. We pay particular attention to directional spillovers, and in so doing provide important evidence about how shocks to job separation spread differentially in different regimes, or different points in the business cycle.

Our work builds on a substantial literature. Manning (1994) found strong contiguity effects in his analysis of county labour market data. Martin (1994) meanwhile found co-integrating relationships between regional and national unemployment rates, suggesting the existence of equilibrium differentials between regions and a tendency for shocks to be transmitted speedily across geographies.

Several papers, including Evans and McCormick (1994), Taylor and Bradley (1994), McCormick (1997), and Johnes and Hyclak (1999) investigate the role of, inter alia, housing markets and long term migration trends in determining regional response to macroeconomic shocks. As the core region grows, migration from the periphery tends to increase, thereby easing labour market shortages in the core while reducing unemployment in the periphery - so long as this migration is not choked off by housing market constraints. These papers uncover a marked change, observed in the 1990s recession, in the pattern of regional labour market response to macroeconomic fluctuations in the UK, with regions that had previously been characterised by relatively lower levels of unemployment being relatively hard hit. Elsewhere, using data for Finland, Hämäläinen and Böcherman (2004) note that regions characterised by high rates of labour turnover tend to have lower rates of net outmigration. 
More recent work for the UK has been scant ${ }^{1}$, but Sensier and Artis (2011), building on teh US work of Crone (2006), investigate the spread of recession over time across the counties of Wales. The work reported in the present paper represents an extension of this to the whole of Great Britain, while simultaneously employing more recently developed methods of analysis to throw greater light on the nature of the transmission mechanisms.

Recent years have witnessed a growing interest in empirically investigating the worker reallocation process within the standard Diamond Mortensen - Pissarides search and matching framework (Diamond, 1982; Mortensen and Pissarides, 1994; Pissarides, 1985, 2000). Most of the studies use descriptive measures to capture the important features of the flows into and out of unemployment, and hence evaluate how the changes in flow rates affect the changes in unemployment rate (Hall, 2005; Fujita and Ramey, 2006, 2009; Shimer, 2007; Elsby et al., 2009). More recently, noting that descriptive measures are unable to account for the labour market response to various shocks to the system, researchers have turned to VARs to examine the dynamics of workers' job seeking (and employers' recruiting) processes.

Among these, Fujita (2011) uses a structured trivariate vector autoregression (VAR) model consisting of inflow, outflow and vacancy rates to evaluate whether the job separation or job finding rate plays the dominant role in the dynamics of US labour market. ${ }^{2}$ Given that the mechanisms

\footnotetext{
${ }^{1}$ There has, however, developed a literature on regional convergence in Europe - see, for example, Duranton and Monastiriotis (2002), Corrado et al. (2005) - but the focus of this work is on long run equilibrium differentials rather than on short term responses to cyclical fluctuations.

${ }^{2}$ In this paper, we use inflow rate and separation rate interchangeably, outflow and job finding rate interchangeably
} 
underlying the job search/matching process can vary over time, Campolieti et al. (2014a) extend the research of Fujita (2011) by using time-varying parameter vector autoregressions (TVPVAR) for data from North America (the USA and Canada) and Europe (France, Spain and the UK). Instead of focusing on the interrelationship between inflow, outflow and vacancy rates, Canova et al. (2013) look into how inflow, outflow, and unemployment rates react to technology shocks in a six-variable VAR model that consists of inflows, outflows, vacancies, price for new equipment, labour productivity and hours. These studies using VAR models for the labour market all focus on aggregate data at national level. As a result, their findings can overlook important nuances, and even be misleading, when the job creation and destruction process at regional level is more of a concern. ${ }^{3}$

The interregional transmission of labour market shocks is an important issue for a number of reasons. If such transmission is slow, then the pace of economic growth will typically differ across space, and in extreme cases this can mean that macroeconomic policies that are well suited to one part of the country may not serve other parts so well. In the UK, there is currently some concern that the transmission mechanism that has, in the past, ensured that growth in leading regions trickles down to other areas, is either no longer working well or is working much more slowly as the economy recovers from the Great Recession (Townsend and Champion, 2014). This, then, is an appropriate time to re-investigate the mechanisms, using newly developed methods that allow more detailed analysis of the nature of transmission than

\footnotetext{
${ }^{3}$ Papers such as Garrett (2003), Abadir and Talmain (2002), Forni and Lippi (1997, 99) show that the statistical properties of aggregate data can be very different from that of their disaggregate components.
} 
was heretofore possible.

This paper focuses on the complex interrelationships between unemployment inflow, outflow and vacancy rates of $11 \mathrm{UK}$ regions. Altogether, we have 33 variables that might be all interrelated. In order to avoid imposing 'incredible' restrictions in the sense of Sims $(1972,1980)$, we use an unrestricted VAR to model the complicated interlinkages between thirty-three endogenous variables ${ }^{4}$. This sets the paper apart from the available studies such as Burda and Profit (1996) and Burgess and Profit (2001), which use single equation models or VARs of much smaller size. In addition, to account for the possible nonlinear effect in the interactions between VAR variables, we assume the regime changes are governed by a logistic smooth transition function (Maddala, 1977; Teräsvirta, 1994). Our estimation approach is Bayesian. Papers such as Banbura et al. (2010), Koop (2011) and Gefang (2014) show that large Bayesian VARs provide better forecasts and more sensible impulse response analysis than their non-Bayesian counterparts. Popular shrinkage methods for large Bayesian VARs include the traditional Minnesota prior of Doan et al. (1984) and Litterman (1986) and its natural variants (Kadiyala and Karlsson, 1997; Banbura et al., 2010), the stochastic search variable selection (SSVS) prior of George et al. (2008), and the family of SSVS plus Minnesota priors of Koop (2011). Recently, Gefang (2014) introduces doubly adaptive elastic-net Lasso (DAELasso) for VAR shrinkage. Compared to other Bayesian VAR methods, DAELasso is more data based. In this paper, we use DAELasso for VAR parameter shrinkage so as to let the data speak.

\footnotetext{
${ }^{4}$ The inflow, outflow and vacancy rates are $\mathrm{I}(0)$.
} 
We use the generalized spillover measure (GSM) of Diebold and Yilmaz (2012) to investigate the shocks propagating mechanism between variables and regions. GSM is currently among the most popular tools for investigating spillover effects using VAR models (Antonakakis, 2012; Altera and Beyer, 2014) . GSM does not require orthogonal innovations to decompose the forecast error variances, which is especially desirable when there is a lack of theoretical guidance on identifying the structure of a complex dynamic system. Various structured VAR models are used in the literature on the labour market. Papers such as Braun et al. (2007) and Canova et al. (2013) assess the effect of different types of shocks to the labour market by including variables such as productivity and hours into the system. Fujita (2011), however, shows that labour market reallocation exhibits a qualitatively similar pattern regardless of the nature of the shocks. Fujita (2011) and Campolieti et al. (2014a) use sign restrictions consistent with the Beveridge curve relationship to differentiate the aggregate negative/positive shocks depending on how unemployment and vacancies respond to such shocks. These existing studies all look into aggregate data at national level. To implement sign restrictions becomes more difficult, if not impossible, for our large VAR that involves 33 endogenous regional labour market variables. To start with, as shown in Wall and Zoega (2002), the Beveridge curve relationship does not necessarily hold for every UK region. Next, it becomes even harder to impose meaningful structures on how changes in one variable might affect variables in other regions. To circumvent these problems, we resort to GSMs to explore the spillover effects in a data based manner.

Our empirical results shed new light on the interrelationship between 
job finding, job separation and vacancy rates of $11 \mathrm{UK}$ regions. Our model comparison results indicate that regime changes in the dynamic system are governed by confidence levels. The plot of the transition function shows two marked dips: the first happened right after the Great Recession begins in Q2 2008, while the second happened in the second half of 2010. Moreover, we find that regardless of the regimes, for each variable, both the volatility spillovers to and from other variables are high, which provides clear evidence for the close interdependence between UK regional labour markets. Analysis of net spillovers shows that, in general, shocks to job separation rates tend to spread into job finding and vacancy rates. By contrast, vacancy rates are usually at the receiving end of shocks transmitted from the unemployment flows. The impact of shocks to outflow rates are mixed. However, there is strong evidence that shocks to outflow rates have larger impact on vacancy rates compared to shocks to inflow rates or vacancy rates.

The remainder of the paper is organised as follows. Section 2 introduces the econometric methods. Section 3 presents the empirical analysis. Section 4 concludes. Bayesian methods and explanations on GSM are provided in an online appendix (https://ideas.repec.org/p/lec/leecon/14-08.html).

\section{Econometric Methods}

\subsection{Model and Bayesian Methods}

The United Kingdom has a relatively flexible labour market (Owen and Green, 1989). The population is concentrated, with large cities linked by a good transport infrastructure. Hence a worker can easily commute to 
take up a job in a region other than the one in which she resides - though of course this comes at a cost. Moreover, with a high share of private ownership in the housing market, both in the form of owner-occupation and private rentals, migration is also an available choice. Consequently, changes in the economic fortunes of one region of the country are typically transmitted to other regions through a process of local labour market adjustments.

When we model the Diamond-Mortensen-Pissarides bilateral search/matching mechanism at regional level, it is necessary therefore to allow for interregional interactions. Moreover, there is considerable evidence of nonlinearity in the dynamics of job search/matching process (eg. Shimer, 2007; Elsby et al., 2009; Campolieti et al., 2014a). Our modelling strategy therefore needs to allow both for regional spillover and possible nonlinear effects.

Let $y_{t}$ be a vector containing inflow, outflow and vacancy rates for 11 UK regions. We model the dynamic linkages between these variables using an unrestricted smooth transition VAR:

$$
y_{t}=\Phi+\Sigma_{h=1}^{p} \Gamma_{h} y_{t-h}+F\left(z_{t}\right)\left[\Phi^{z}+\Sigma_{h=1}^{p} \Gamma_{h}^{z} y_{t-h}\right]+\varepsilon_{t}
$$

where $\varepsilon_{t}$ is a white noise process, that is $E\left(\varepsilon_{t}\right)=0, E\left(\varepsilon_{s} \varepsilon_{t}^{\prime}\right)=\Sigma$ for $s=t$, and $E\left(\varepsilon_{s} \varepsilon_{t}^{\prime}\right)=0$ for $s \neq t$.

The regime changes are assumed to be captured by the following first order logistic smooth transition function as explained in Maddala (1977) 
and Teräsvirta (1994): ${ }^{5}$

$$
F\left(z_{t}\right)=\left[1+\exp \left\{-\gamma\left(z_{t-\pi}-c\right) / \sigma\right\}\right]^{-1}
$$

Function (2) is defined by the transition variable $z_{t-\pi}$, where $\pi$ is the lag indicator. The parameter $\gamma$ (which is non-negative) determines the speed of the smooth transition. We can see that when $\gamma \rightarrow \infty$, the transition function becomes a Dirac function and the model (1) becomes a two-regime threshold VAR model along the lines of Tong (1983). When $\gamma=0$, the logistic function becomes a constant (equal to 0.5), and the nonlinear model (1) collapses, in this special case, to a linear $\operatorname{VAR}(p)$. The parameter $c$ is the point of inflection of the function and so is the threshold around which the dynamics of the model change. The value for the parameter $\sigma$ is chosen by the researcher; it could, as a particularly simple example, be set to one. However, if we set $\sigma$ equal to the standard deviation of the process $z_{t}$, this effectively normalises $\gamma$ such that we can give this parameter an interpretation in terms of the precision of $z_{t}$ (i.e., $\left.\sigma^{-1}\right)$ which, in turn, aids in defining the prior for $\gamma$. The transition from one extreme regime to the other is smooth for reasonable values of $\gamma$.

The principle underlying the logistic smooth transition VAR (LSTVAR) is that as $z_{t}$ increases, moving from well below some threshold $c$ to well above this threshold, the dynamics of the vector process $y_{t}$ changes from one regime to another. That is, if $z_{t}$ is very low - that is, well into what we will call the lower regime - then the process $y_{t}$ may be generated by the

\footnotetext{
${ }^{5}$ For a comprehensive review on smooth transition VAR models, please refer to Hubrich and Teräsvirta (2013).
} 
VAR model as follows.

$$
y_{t}=\Phi+\Sigma_{h=1}^{p} \Gamma_{h} y_{t-h}+\varepsilon_{t}
$$

However, when $z_{t}$ is very high - well into what we will call the upper regime - then the process $y_{t}$ may be generated by the VAR given by

$$
y_{t}=\left(\Phi+\Phi^{z}\right)+\Sigma_{h=1}^{p}\left(\Gamma_{h}+\Gamma_{h}^{z}\right) y_{t-h}+\varepsilon_{t}=\Phi^{1}+\Sigma_{h=1}^{p} \Gamma_{h}^{1} y_{t-h}+\varepsilon_{t}
$$

The transition between these two regimes is smooth - governed by the values of the parameters in the smooth function of $z_{t}$ denoted by $F\left(z_{t}\right)$. The value of $F\left(z_{t}\right)$ is bounded by 0 and 1 since $F\left(z_{t}\right)=0$ when $z_{t}=-\infty$, and $F\left(z_{t}\right)=1$ when $z_{t}=\infty$. The presence in the model of the smooth transition between regimes allows nonlinearity to be accommodated, while the inclusion of region-specific data in our vector of endogenous variables allows for the presence of spillover effects.

Following Gefang and Strachan (2011), we rewrite the model in (1) as

$$
y_{t}=\left(1-F\left(z_{t}\right)\right)\left[\Phi+\Sigma_{h=1}^{p} \Gamma_{h} y_{t-h}\right]+F\left(z_{t}\right)\left[\Phi^{1}+\Sigma_{h=1}^{p} \Gamma_{h}^{1} y_{t-h}\right]+\varepsilon_{t}
$$

which is equivalent to equation (1), but this representation shows explicitly the parameters in the different regimes. Note that since $z_{t}$ is a continuous variable and $F\left(z_{t}\right)$ is a continuous function of $z_{t}$, model (1) implies an infinite set of dynamic processes.

Let $x_{t}=\left(1, y_{t-1}^{\prime}, \ldots, y_{t-p}^{\prime}\right), x_{t}^{\theta}=\left[x_{t} F\left(z_{t}\right) x_{t}\right], Y=\left(y_{1}, y_{2}, \ldots, y_{T}\right)^{\prime}, X^{\theta}=$ $\left(x_{1}^{\theta \prime}, x_{2}^{\theta \prime}, \ldots, x_{T}^{\theta \prime}\right)^{\prime}, B=\left(\Phi, \Gamma_{1}, \ldots, \Gamma_{p}, \Phi^{z}, \Gamma_{1}^{z}, \ldots, \Gamma_{p}^{z}\right)^{\prime}$ and $E=\left(\varepsilon_{1}, \varepsilon_{2}, \ldots, \varepsilon_{T}\right)^{\prime}$. 
We rewrite model (1) in a more compact form as

$$
Y=X^{\theta} B+E
$$

where $E$ is a $T \times N$ matrix for i.i.d. error terms with its $t^{\text {th }}$ row distributed as $\mathrm{N}(0, \Sigma)$.

Vectorizing the matrices, we can transform model (6) into

$$
y=\left(I_{n} \otimes X\right) \beta+e
$$

where $y=\operatorname{vec}(Y), \beta=\operatorname{vec}(B), e=\operatorname{vec}(E)$ and $e \sim N\left(0, \Sigma \otimes I_{T}\right)$. Note that the dimension of $\beta$ is $N^{2} k \times 1$.

Equation (7) cannot be estimated using frequentist methods when the number of VAR coefficients exceeds the number of observations. The Bayesian VAR approach, which shrinks parameters by employing appropriate priors, has proved powerful for analyzing such dynamic models of large dimensions (e.g., Sims, 1972, 1980; Banbura et al., 2010; Koop, 2011). Recently, Gefang (2014) has introduced the Bayesian DAELasso method for VAR shrinkage. Compared with other Bayesian VAR approaches, DAELasso is more attractive for our current purposes as it does not discriminate between the endogenous variables.

The DAELasso estimator for a VAR is defined as following:

$$
\hat{\beta}_{d L}=\arg \min _{\beta}\left\{\left[y-\left(I_{n} \otimes X\right) \beta\right]^{\prime}\left[y-\left(I_{n} \otimes X\right) \beta\right]+\sum_{j=1}^{N^{2} k} \lambda_{1, j}\left|\beta_{j}\right|+\sum_{j=1}^{N^{2} k} \lambda_{2, j} \beta_{j}^{2}\right\}
$$


where $\lambda_{1, j}$ and $\lambda_{2, j}$, for $j=1,2, \ldots, N^{2} k$, are positive tuning parameters associated with the $L_{1}$ and $L_{2}$ penalties, respectively. We allow for different tuning parameters for different $\beta_{j}$ to allow for different degrees of shrinkage.

The parameters in equation (8), including $\gamma$ and $c$ in the smooth transition function (2), can be estimated using full conditional Gibbs samplers (Geman and Geman, 1984). To save space, we present the priors, posteriors, full Gibbs scheme and - recognising that the choice of priors can be important - prior sensitivity analysis in the online appendix.

\subsection{Generalised Spillover Measure}

We use the GSM developed by Diebold and Yilmaz (2012) to decompose forecast error variances of each variable into components that are associated with various shocks to the dynamic system modelled in equation (1). The GSM does not require orthogonal innovations, hence the variance decompositions are invariant to the ordering of the variables. This feature is particular relevant to our current research as there is a lack of economic theories regarding how shocks propagate in the complicated system involving inflow, outflow and vacancy rates of many different regions.

The original GSMs are developed for linear VARs. As the smooth transition function (2) is continuous, we can calculate GSMs for any value of $F\left(z_{t}\right)$ that may be of interest. For example, if we are concerned about the situation where $z_{t}=z_{\tau}$, model (1) turns into

$$
y_{t}=\left(\Phi+\Phi^{z} F\left(z_{\tau}\right)\right)+\Sigma_{h=1}^{p}\left(\Gamma_{h}+\Gamma_{h}^{z} F\left(z_{\tau}\right)\right) y_{t-h}+\varepsilon_{t}
$$


Let $\Psi_{h}=\Gamma_{h}+\Gamma_{h}^{z} F\left(z_{\tau}\right)$, we have the familiar linear VAR form discussed in section 2 of Diebold and Yilmaz (2012). Using the standard technique detailed in section 2.1 of Lütkepohl (2007), we can write equation (9) in its moving average representation:

$$
y_{t}=\mu+\sum_{i=0}^{\infty} A_{i} \varepsilon_{t-i}
$$

where $\mu$ is the mean, and the moving average coefficients $A_{i}$ can be computed recursively using $A_{0}=I_{N}$, and $A_{i}=\sum_{j=1}^{i} A_{i-j} \Psi_{j}$.

Following Diebold and Yilmaz (2012), based on $A_{i}$ and $\Sigma$, we can then compute the own variance shares for variables $y_{n}$ that are due to shocks to the variable itself, directional volatility spillovers received by the variable $y_{n}$ from shocks to other variables and directional volatility spillovers transmitted by the variable $y_{n}$ to other variables. More importantly, we can evaluate net spillovers and net pairwise spillovers to examine how shocks are transmitted across variables and regions. Again, for brevity, we relegate the details of how we compute these spillovers to the online appendix.

\section{Empirical Analysis}

\subsection{Data Description}

The main data series used in the present analysis provide labour market information within standard UK regions and come from Nomis. ${ }^{6}$ Monthly

\footnotetext{
${ }^{6}$ Nomis, previously known as the National Online Manpower Information System, produces detailed spatial labour market data and makes these available at www.nomisweb.co.uk.
} 
data are published on flows of workers into and out of the unemployment register, notified vacancies, ${ }^{7}$ unemployment (known as the claimant count) and unemployment rates (workplace-based estimates). For reasons of data availability, our sample period runs from May 2002 to November 2012. We seasonally adjust the variables in our analysis using the X-12-ARIMA seasonal adjustment program of the US Census Bureau. There is an obvious step change in the seasonally adjusted vacancy data in June 2003 when the Employer Direct Online facility was introduced - this allows employers to register vacancies at job centres much more easily than was previously possible. We use a dummy variable to control for this change in data handling procedures. In line with the literature (Pissarides and Wadsworth, 1989; Albæk and Hansen, 2004; Burgess and Turon, 2005), we calculate the inflow rate $(s)$ as the ratio of the flows of workers onto the unemployment register to the number of employed workers, the outflow rate $(f)$ as the ratio of the flows out of the unemployment register to the number of people who are unemployed, ${ }^{8}$ and the vacancy rate $(v)$ as the ratio of notified vacancies to the number of labour force (sum of the employed and unemployed). Finally, to remove the excess volatility featured in high-frequency monthly data, we

\footnotetext{
${ }^{7}$ Nomis also publish the stock of unfilled vacancies, which tend to have unspecified time lags because follow up takes time. By contrast, notified vacancies do not have the time lag problem. Qualitatively, notified vacancies are similar to the US help wanted index, vacancy posting used in papers such as Fujita (2011) and Campolieti et al. (2014a). The data on vacancies are based on notifications made by employers to job centres, and only a proportion of all vacancies are notified. Since 'this proportion will tend to vary between different areas and different sectors of the economy' (Machin and Christian, 2002), we must acknowledge the possibility that this biases parameter estimates. However, as noted by Coles and Petrongolo (2013), 'the bulk of unemployment is experienced by unskilled and semi-skilled workers' for whom job centre vacancies are indeed most relevant.

${ }^{8}$ As argued by Shimer (2007), in a steady state, the relationship between worker flows and the unemployment rate can be expressed as $s /(s+f)$ where $s$ is the inflow rate and $f$ the outflow rate. The data we use match this function well.
} 
use quarterly averages of the monthly data in our analysis. Altogether, we consider 11 regions, i.e., North East (NE), North West (NW), Yorkshire and The Humber ( $\mathrm{Y} \& \mathrm{H})$, East Midlands (EM), West Midlands (WM), East, London, South East (SE), South West (SW), Wales and Scotland.

Studies such as Friedman (1997), Acemoglu and Scott (1994), and Stock and Watson (1999) suggest that the regional labour market may be affected by macroeconomic variables that are linked to expectations, output, inflation and monetary policies at national level. Moreover, it is possible that regime changes in the interrelationships between regional variables might be governed by their national aggregates. Thus, we consider the following 7 UK macro series as candidate transition variables for equation (2): confidence indicators produced in consumer opinion surveys, total industrial production, registered unemployment rate, money supply (M2), total unfilled job vacancies, the consumer price index and interest rate (discount rate). The first six series are obtained from OECD Main Economic Indicators, while interest rate is from International Financial Statistics. The raw data are in monthly frequencies. Again, we use X-12-ARIMA of the US Census Bureau to seasonally adjust the variables where needed, and take the quarterly average to eliminate any excess volatilities.

The standardised inflow, outflow and vacancy rates for the 10 standard regions of Great Britain are plotted in Figures 1-3. London and the South East together account for around 38 per cent of Gross Value Added (GVA) in Great Britain, with GVA per capita falling towards the geographical periphery. 
There is pronounced evidence of a common trend in each figure. ${ }^{9}$ Empirical literature on macro time series at disaggregated levels identify the common trend as a factor which is driven by the broad business cycle trends for the economy as a whole (Altonji and Ham, 1990; Kose et al., 2003; Campolieti et al., 2014b). Since we are more interested in the effect of regional specific shocks, we remove the effect of the common factor from the data before estimating the model (1). ${ }^{10}$

Figure 1: Standardised Inflow Rates

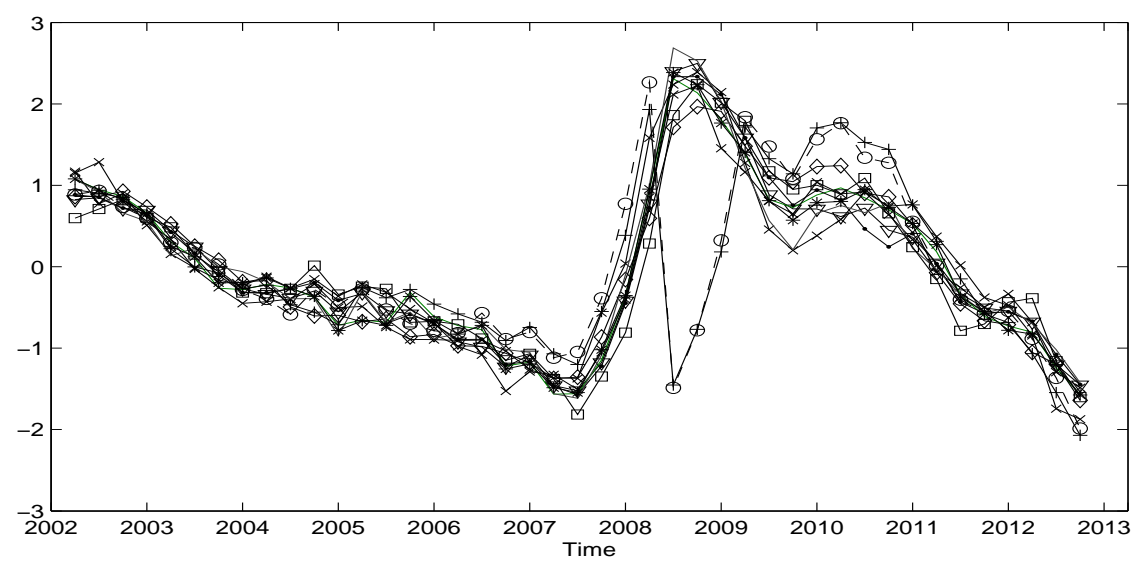

\footnotetext{
${ }^{9}$ To avoid the graphs becoming too messy, we omit labels for the multiple series. There are, however, some notable cases of regions where, with the onset of the Great Recession in 2008, the flows into and out of employment differed from the bulk of other regions. In Figure 1, we see that there are two regions that experienced a particularly dramatic fall in the inflow rate, and that this rate recovered more quickly than elsewhere - the two regions are Scotland and Wales. Likewise, in Figure 2 the outflow rates of these two regions at this time take deeper drops.

${ }^{10}$ We use Kalman filter to identify one national factor that affects inflow rates of all regions. In the same manner, we identify the national factor for outflow and vacancy rates respectively.
} 
Figure 2: Standardised Outflow Rates

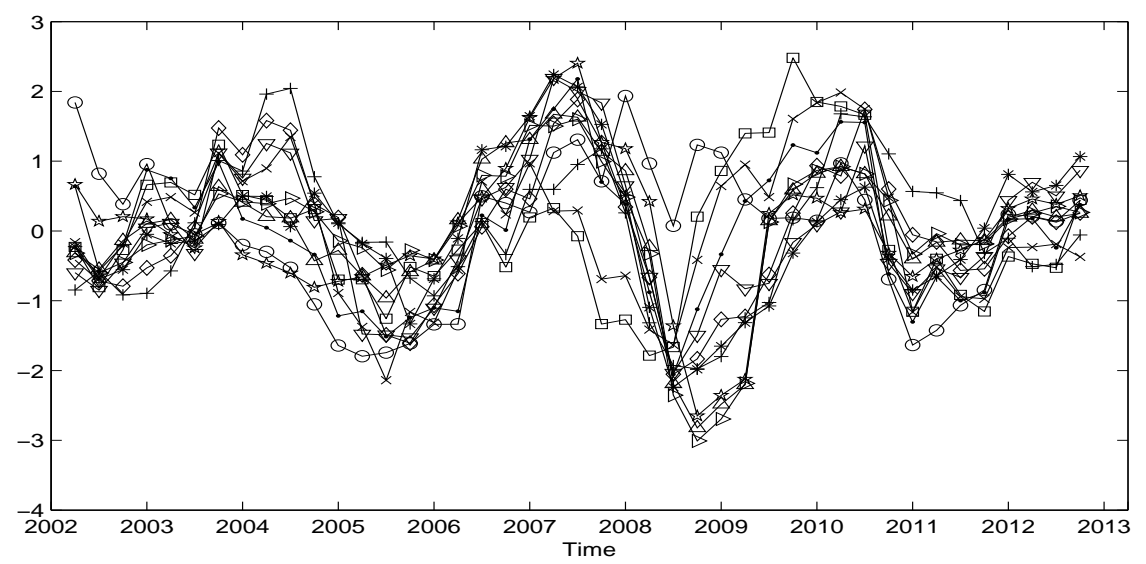

Figure 3: Standardised Vacancy Rates

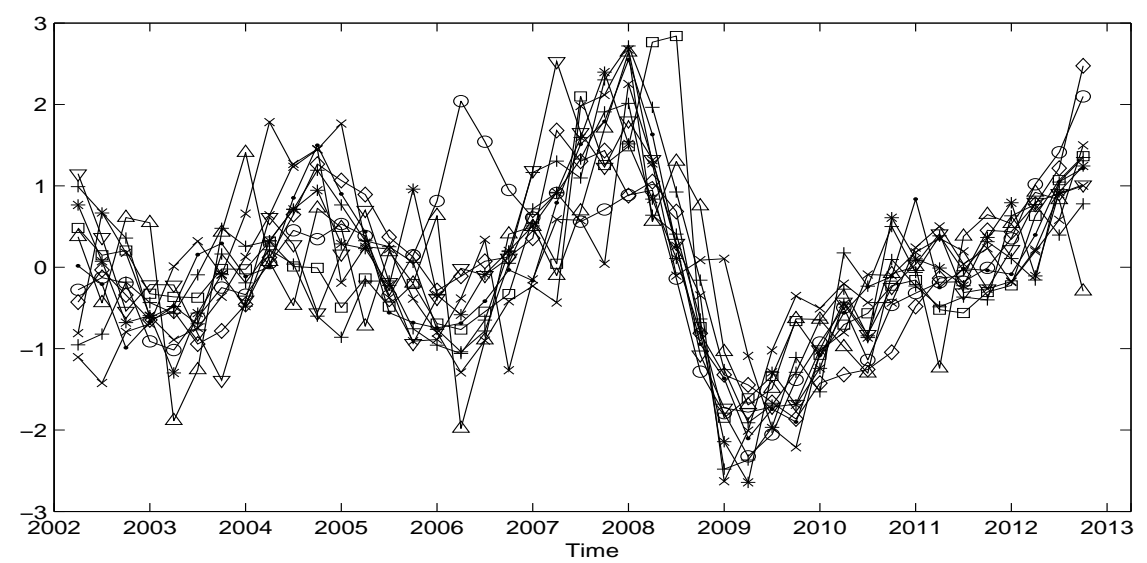

\subsection{Model Comparisons}

The Akaike information criterion (AIC) and Bayesian information criterion (BIC) suggest a lag length of 1 or 2 quarters for linear trivariate VAR models that contain the inflow, outflow and vacancy rates for each region. For the large non-linear VAR model that contains all the 33 UK regional inflow, 
outflow and vacancy rates, we consider a large number of alternative VAR models. The VARs have lag lengths of 1 or 2 quarters; each of the transition variables is considered in logged level terms and in terms of first differences (growth rates) and each of these (level or growth) transition variables appears in the model separately with the lag length of $1,2,3$ or 4 to allow for a long enough time period during which the regime of labour market interactions begins to react to macroeconomic changes. Hence we estimate $(2 \times 7 \times 2 \times 4=) 112$ candidate models differentiated by the lag order of VAR, the transition variable (and whether that appears in level or change terms), and the lag order of the transition variable. In empirical work, each Gibbs sampler runs 1,1000 iterations with the first 1000 discarded.

We use the BIC defined below for model comparisons.

$$
B I C=-\log (\hat{l})+0.5 \log (T) d
$$

where $\hat{l}$ is the maximum of the likelihood function and $d$ is the number of parameters including the VAR coefficients and the parameters in the logistic function. The method is appealing as it does not involve integration and does not depend on the priors (Wasserman, 2000).

The top 10 preferred models as selected by BIC are listed in Table 1. The general finding is that the lagged consumer confidence indicator in levels is the most effective series in the identification of regime changes, followed by the growth rate of industrial production. Models with transition variables associated with inflation and monetary policy also ranked highly. However, models with transition variables related to national unemployment 
and vacancies do not appear in the top 10 selected models. Our result that consumer confidence level outperforms the rest of the candidate variables in leading regime changes in intra- and inter- regional labour market interdependencies is in the spirit of Acemoglu and Scott's (1994) finding that consumer confidence can forecast UK unemployment changes better than other macroeconomic variables. ${ }^{11}$

As shown in Kass and Raftery (1995), the Bayes factor can be approximated by the exponential of $-\frac{1}{2}$ times the differences between two models' $B I C$ measures calculated by equation (11). If we assume uniform prior model probabilities, the preferred model will receive almost $100 \%$ of the posterior probability. Since there is no strong theoretical justification for assigning models different prior probabilities, we take the model selected by BIC as our preferred model and use it for the rest of the analysis.

Table 1: Model Comparison Results

\begin{tabular}{|c|c|c|c|c|}
\hline Model & Transition Variable & $\begin{array}{l}\text { Lag Length of Transi- } \\
\text { tion Variable }\end{array}$ & Order of VAR & $\mathrm{BIC}$ \\
\hline 1 & Consumer Confidence Indicators ( level) & 4 & 2 & -34.85 \\
\hline 2 & Industry Production (first difference) & 2 & 2 & 26.80 \\
\hline 3 & CPI (first difference) & 4 & 2 & 42.50 \\
\hline 4 & M2 (first difference) & 2 & 2 & 46.89 \\
\hline 5 & CPI ( first difference) & 1 & 2 & 62.11 \\
\hline 6 & Interest Rate ( first difference ) & 1 & 2 & 72.70 \\
\hline 7 & Consumer Confidence Indicators ( level ) & 2 & 2 & 73.19 \\
\hline 8 & M2 (first difference) & 1 & 2 & 79.37 \\
\hline 9 & Interest Rate ( first difference ) & 4 & 2 & 80.13 \\
\hline 10 & Consumer Confidence Indicators ( first difference) & 4 & 2 & 100.87 \\
\hline
\end{tabular}

\footnotetext{
${ }^{11}$ Although further investigation on why consumer confidence plays such an important role goes beyond the scope of the current paper, we would like to point out that recent papers that focus on individuals' dual role as consumers and workers might provide more insights on this issue. For instance, Crouch (2012) explores the possibility of resolving the tension between an economy's need for both flexible workers and confident consumers.
} 


\subsection{Nonlinear Effect in the Most Preferred Model}

We plot the value of the smooth transition function against time for the most preferred model in Figure 4. Note that here the transition indicator is consumer confidence in levels, and the lag length of the indicator is one year. The most striking feature of the plot is the huge impact of the Great Recession which starts in 2008. Before then, the values taken by the transition indicator are relatively high and the changes are rather smooth. After the recession hit, the regime changed abruptly. The value of the transition function jumped towards a very low level close to zero. This situation only starts to get better after early 2010. However, the recovery is very short lived, and the value of the logistic function takes another dive at the end of 2010. Interestingly, we find that the first drop to the lower regime happens after the Great Recession sets in in 2008, yet the second fall in the regimes happens well before growth once again slows in 2012. Overall, our result supports the notion that the Great Recession greatly changed the regional and interregional job search/matching process in the UK. We investigate further how this switch manifests itself in the next section of the paper. 
Figure 4: Transition Function

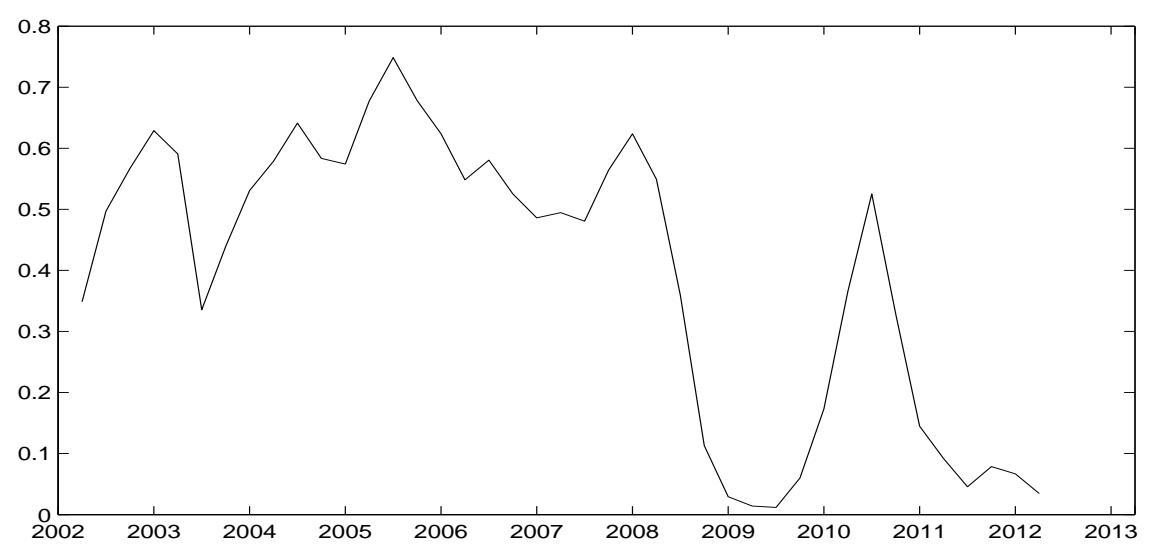

\subsection{Spillovers}

We study how shocks are transferred between variables by investigating spillovers under three hypothetical regimes: a lower regime where the value of the transition function is 0 , an upper regime where the value of the transition function is 1 , and a middle regime where the transition function is 0.5. In practice, as we have seen the upper regime approximates the position before the Great Recession while the lower regime approximates the position since. For each regime, we consider two forecasting horizons: $h=2$ and $h=4$. 


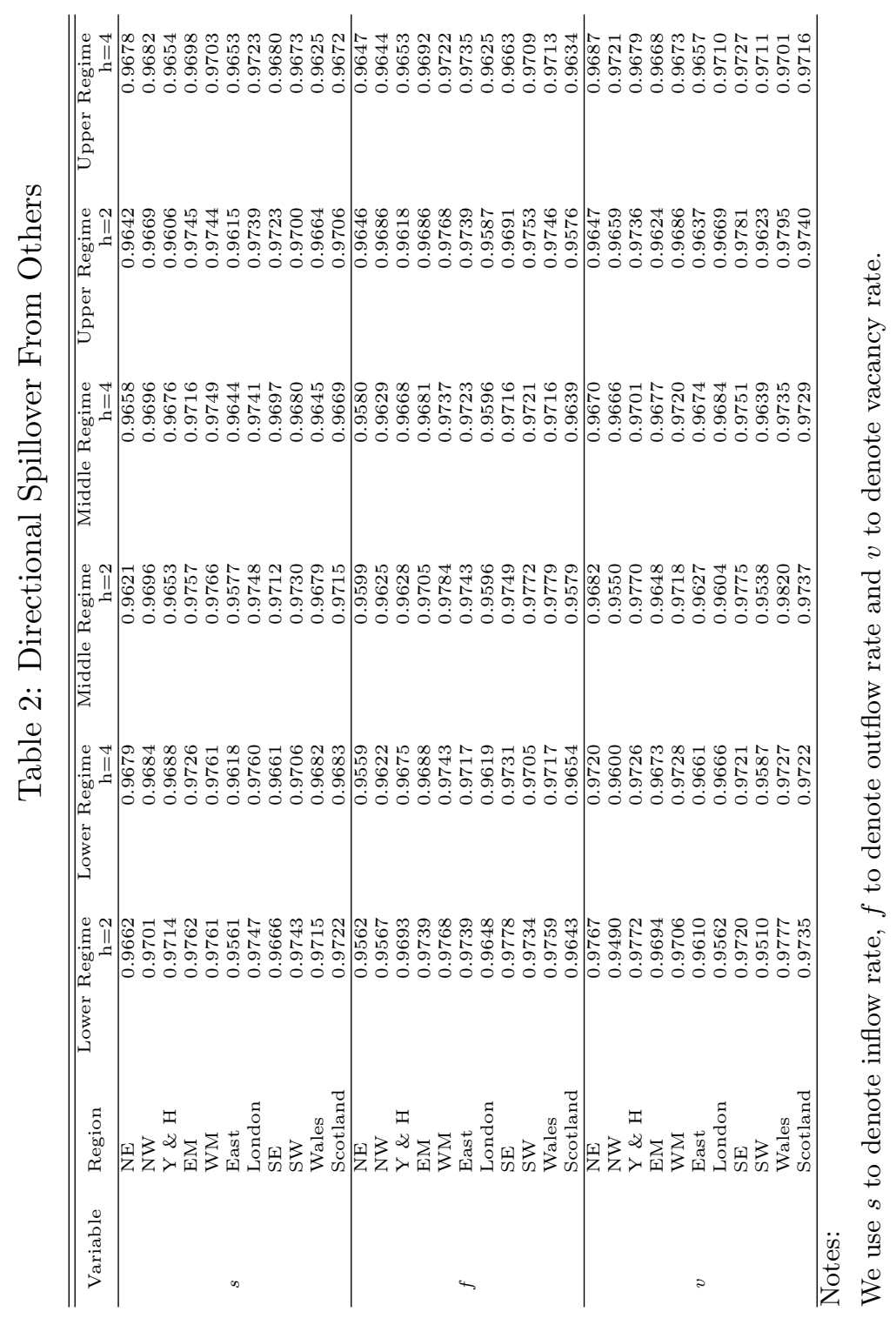


Table 2 presents the directional spillover from other variables. For each variable, the spillovers from others are high. Generally, the values range between $95 \%$ to $98 \%$ for each regime. There are some slight differences between the regimes though. For example, variables typically receive fewer spillovers from other variables when the regime moves from the upper to the lower regime. These findings may explain the relatively slow transmission of economic recovery from the leading regions to other parts of the country over the course of the 2013-14 upturn (compared, that is, with earlier recoveries).

Table 3 shows the directional volatility spillover to other variables. There is much more variation across regions in the extent of spillover in this table than in Table 2; while labour market conditions spread across space, the economic structure of some regions (specialising perhaps in industries with strong input-output linkages) means that they are more likely than others to serve as leaders in the diffusion of labour market shocks. On average, volatilities of inflow and outflow rates tend to have the highest directional spillovers to others at the lower regime, followed by the middle regime, then have much smaller directional spillovers to others at the upper regime. The scenario related to vacancy is mixed. Directional spillovers to others tend to have the largest values at the upper regime, followed by the middle regime, then the upper regime. It appears that a change in an unemployment flow or in vacancies in one region has greatest potential to impact on other regions in regimes that push the levels of these variables to be high; this in turn provides some stability to benign regimes.

The large values of directional spillovers reported in Tables 2-3 confirm, unsurprisingly, that the 33 endogenous variables we investigated are closely 
interrelated and that it would therefore be inappropriate to ignore interregional linkages when we model the regional labour market. 


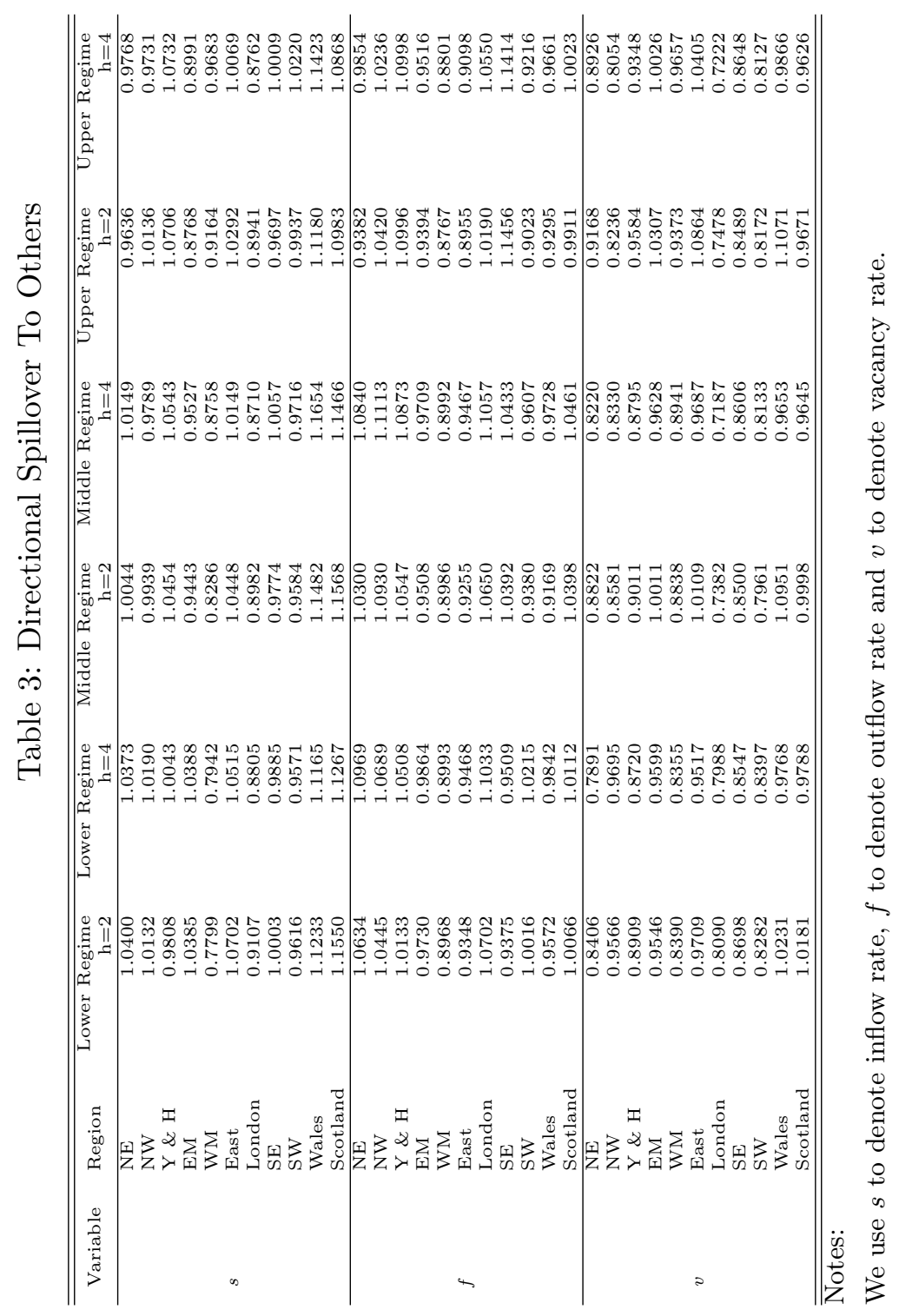




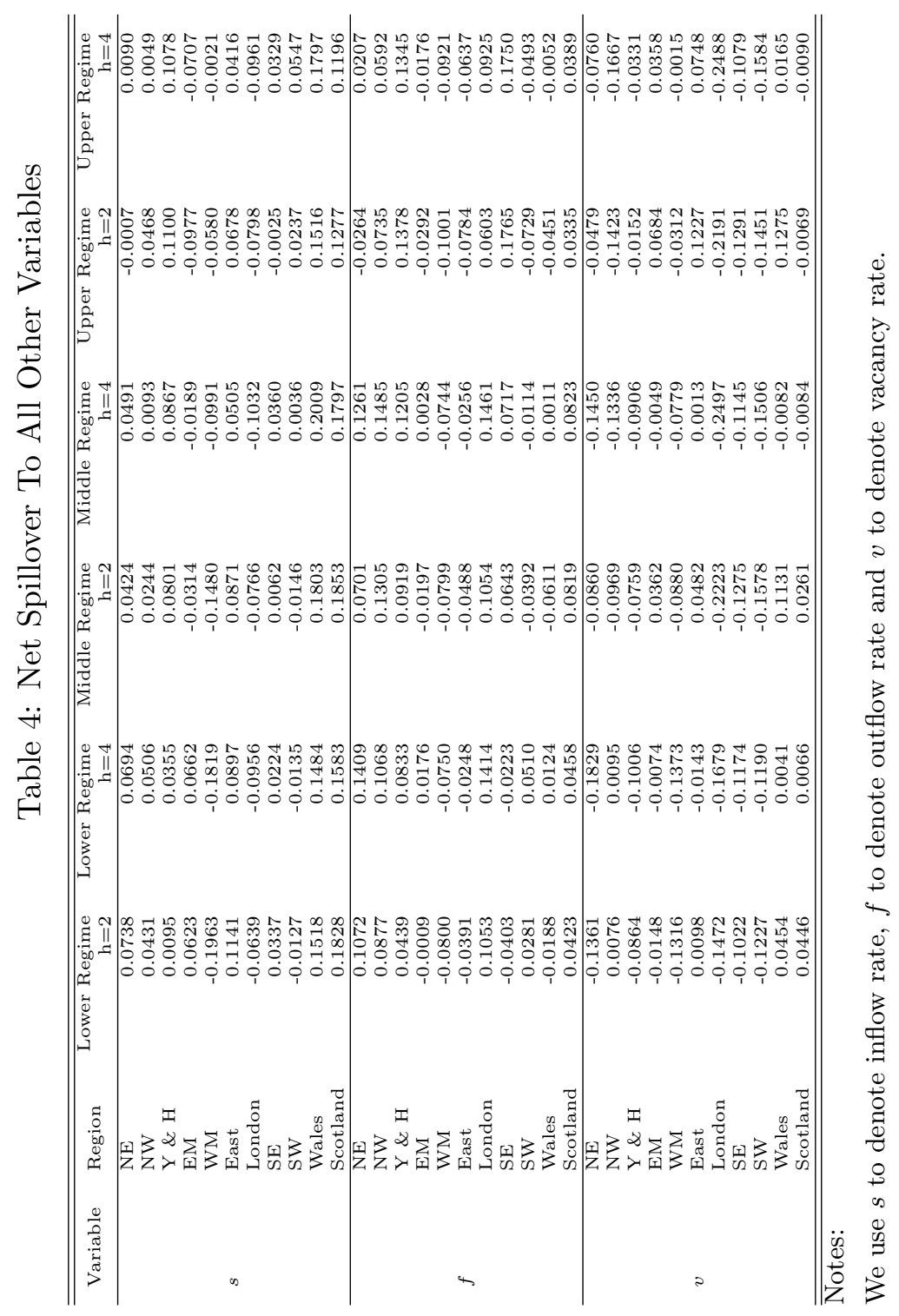


Net spillovers from each variable to all the other variables are reported in Table 4. Observe that shocks to inflow rates tend to have more impact on the volatilities of other variables - with a preponderance of positive figures in this part of the table. The net spillovers associated with Wales and Scotland are particularly high, reflecting the fact that changes in the inflow rate in these regions have marked effects on other aspects of the labour market both within these regions and elsewhere. By way of contrast, the figures in the part of the table that refers to vacancy rates are predominantly negative. The figures related to outflows are mixed. Among them, London exhibits the largest positive net spillovers under the both the lower and upper regimes, this serving to highlight the key leading role played by the capital.

Tables 5-7 report respectively the net impact of shocks to one region's inflows on inflows of all other regions, the net impact of shocks to one region's inflows on all outflows, and the net impact of shocks to one region's inflows on vacancies of all regions. Table 5 shows that the volatility in inflows associated with the South East, South West and Scotland tend to have positive spillovers to inflows of other regions under all regimes. Yorkshire and Humberside and the West Midlands tend to have negative spillovers. The scenarios for other regions are quite mixed. Table 6 shows that shocks to inflows in North East, East, Wales and Scotland tend to make outflows more volatile as a whole, while shocks to inflows in East Midlands, West Midlands, London and South East tend to dampen the volatilities in outflows of all regions. Table 7 provides evidence that in most cases, shocks to inflows tend to increase the volatilities on vacancies.

Tables 8-10 present respectively the net impacts of shocks to one region's 
Table 5: Net Spillovers From Each Regional Inflows To Inflows Of All Other Regions

\begin{tabular}{lrrrrrr}
\hline \hline \multirow{2}{*}{ Region } & $\begin{array}{r}\text { Lower Regime } \\
\mathrm{h}=2\end{array}$ & $\begin{array}{r}\text { Lower Regime } \\
\mathrm{h}=4\end{array}$ & $\begin{array}{r}\text { Middle Regime } \\
\mathrm{h}=2\end{array}$ & $\begin{array}{r}\text { Middle Regime } \\
\mathrm{h}=4\end{array}$ & $\begin{array}{r}\text { Upper Regime } \\
\mathrm{h}=2\end{array}$ & $\begin{array}{r}\text { Upper Regime } \\
\mathrm{h}=4\end{array}$ \\
\hline NE & 0.0118 & 0.0019 & 0.0131 & -0.0017 & -0.0087 & -0.0126 \\
NW & -0.0067 & 0.0027 & 0.0031 & -0.0075 & 0.0132 & -0.0045 \\
Y \& & -0.0337 & -0.0098 & -0.0296 & -0.0036 & -0.0096 & 0.0087 \\
EM & 0.0400 & 0.0393 & -0.0178 & -0.0070 & -0.0565 & -0.0318 \\
WM & -0.1027 & -0.0777 & -0.0738 & -0.0576 & -0.0434 & -0.0190 \\
East & -0.0130 & -0.0063 & -0.0025 & -0.0081 & 0.0079 & -0.0029 \\
London & 0.0261 & -0.0187 & 0.0396 & -0.0307 & 0.0266 & -0.0403 \\
SE & 0.0435 & 0.0091 & 0.0395 & 0.0260 & 0.0200 & 0.0104 \\
SW & 0.0183 & 0.0015 & 0.0009 & 0.0020 & 0.0009 & 0.0054 \\
Wales & -0.0201 & 0.0141 & 0.0022 & 0.0413 & 0.0269 & 0.0510 \\
Scotland & 0.0365 & 0.0439 & 0.0253 & 0.0470 & 0.0227 & 0.0355 \\
\hline \hline
\end{tabular}

Table 6: Net Spillovers From Each Regional Inflows To Outflows Of All Regions

\begin{tabular}{|c|c|c|c|c|c|c|}
\hline Region & $\begin{array}{r}\text { Lower Regime } \\
\mathrm{h}=2\end{array}$ & $\begin{array}{r}\text { Lower Regime } \\
\mathrm{h}=4\end{array}$ & $\begin{array}{r}\text { Middle Regime } \\
\mathrm{h}=2\end{array}$ & $\begin{array}{r}\text { Middle Regime } \\
\mathrm{h}=4\end{array}$ & $\begin{array}{r}\text { Upper Regime } \\
\mathrm{h}=2\end{array}$ & $\begin{array}{r}\text { Upper Regime } \\
\mathrm{h}=4\end{array}$ \\
\hline $\mathrm{NE}$ & 0.0546 & 0.0231 & 0.0293 & 0.0221 & 0.0022 & 0.0095 \\
\hline NW & 0.0129 & 0.0028 & -0.0037 & -0.0188 & 0.0104 & -0.0121 \\
\hline$Y \& H$ & -0.0070 & -0.0013 & 0.0072 & 0.0197 & 0.0140 & 0.0338 \\
\hline EM & -0.0719 & -0.0323 & -0.0768 & -0.0519 & -0.0509 & -0.0407 \\
\hline WM & -0.0835 & -0.0764 & -0.0758 & -0.0435 & -0.0254 & -0.0061 \\
\hline East & 0.0707 & 0.0384 & 0.0564 & 0.0136 & 0.0423 & 0.0131 \\
\hline London & -0.0560 & -0.0759 & -0.0803 & -0.0812 & -0.0850 & -0.0528 \\
\hline $\mathrm{SE}$ & -0.0071 & -0.0138 & -0.0240 & -0.0198 & -0.0171 & -0.0020 \\
\hline SW & 0.0038 & -0.0079 & 0.0082 & -0.0112 & 0.0125 & 0.0130 \\
\hline Wales & 0.0813 & 0.0438 & 0.1013 & 0.0654 & 0.0758 & 0.0623 \\
\hline Scotland & 0.0792 & 0.0301 & 0.0978 & 0.0453 & 0.0634 & 0.0304 \\
\hline
\end{tabular}

Table 7: Net Spillovers From Each Regional Inflows To Vacancies Of All Regions

\begin{tabular}{|c|c|c|c|c|c|c|}
\hline Region & $\begin{array}{r}\text { Lower Regime } \\
\mathrm{h}=2\end{array}$ & $\begin{array}{r}\text { Lower Regime } \\
\mathrm{h}=4\end{array}$ & $\begin{array}{r}\text { Middle Regime } \\
\mathrm{h}=2\end{array}$ & $\begin{array}{r}\text { Middle Regime } \\
\mathrm{h}=4\end{array}$ & $\begin{array}{r}\text { Upper Regime } \\
\mathrm{h}=2\end{array}$ & $\begin{array}{r}\text { Upper Regime } \\
\mathrm{h}=4\end{array}$ \\
\hline $\mathrm{NE}$ & 0.0075 & 0.0444 & -0.0001 & 0.0287 & 0.0058 & 0.0121 \\
\hline NW & 0.0369 & 0.0450 & 0.0250 & 0.0356 & 0.0231 & 0.0215 \\
\hline $\mathrm{Y} \& \mathrm{H}$ & 0.0502 & 0.0466 & 0.1025 & 0.0707 & 0.1056 & 0.0653 \\
\hline $\mathrm{EM}$ & 0.0941 & 0.0592 & 0.0632 & 0.0400 & 0.0097 & 0.0017 \\
\hline WM & -0.0101 & -0.0278 & 0.0016 & 0.0020 & 0.0108 & 0.0230 \\
\hline East & 0.0564 & 0.0577 & 0.0332 & 0.0449 & 0.0176 & 0.0314 \\
\hline London & -0.0341 & -0.0010 & -0.0359 & 0.0087 & -0.0214 & -0.0030 \\
\hline SE & -0.0026 & 0.0272 & -0.0093 & 0.0298 & -0.0054 & 0.0245 \\
\hline SW & -0.0349 & -0.0071 & -0.0237 & 0.0128 & 0.0103 & 0.0363 \\
\hline Wales & 0.0906 & 0.0905 & 0.0768 & 0.0943 & 0.0490 & 0.0665 \\
\hline Scotland & 0.0671 & 0.0844 & 0.0622 & 0.0874 & 0.0416 & 0.0537 \\
\hline
\end{tabular}


outflows on outflows of all other regions, the net impact of shocks to one region's outflows on all inflows, and the net impact of shocks to one region's outflows on vacancies of all regions. Table 8 shows that under all regimes, Yorkshire and Humberside tends to exert a positive effect on volatilities of outflows in other regions, while the West Midlands, East and South West are receivers of outflow volatility spillovers originated from other regions. Perhaps the most interesting feature of this table, though, is the sign reversals that may be observed for some regions as we move from the lower to the upper regime. For example, with $\mathrm{h}=2$, there are positive spillovers out of London in the lower regime, but negative spillovers in the higher regime. In the wake of recession, outflows from the unemployment register in the capital have a positive impact on outflows elsewhere, serving to pull the country as a whole out of recession; but as the economy grows and we move to the upper regime, this effect is reversed.

Table 9 shows that in most cases the impact of shocks to outflows tend to dampen the volatilities in inflows. By way of contrast, Table 10 provides strong evidence that shocks to outflows generally increase the volatilities in vacancies. Note that under the lower and middle regimes, the net spillovers from outflows in London to UK vacancy rate amount to around $10 \%$. At the upper regime, Yorkshire and Humberside, London and South East regions all have a strong positive effect on volatilities in vacancies.

Tables 11-13 present respectively the net impact of shocks to one region's vacancies on vacancies of all other regions, the net impact of shocks to one region's vacancies on all inflows, and the net impact of shocks to one region's vacancies on outflows of all regions. Table 11 shows that the East Midlands, 
Table 8: Net Spillover From Each Regional Outflows To Outflows Of All Other Regions

\begin{tabular}{|c|c|c|c|c|c|c|}
\hline Region & $\begin{array}{r}\text { Lower Regime } \\
\mathrm{h}=2\end{array}$ & $\begin{array}{r}\text { Lower Regime } \\
\mathrm{h}=4\end{array}$ & $\begin{array}{r}\text { Middle Regime } \\
\mathrm{h}=2\end{array}$ & $\begin{array}{r}\text { Middle Regime } \\
\mathrm{h}=4\end{array}$ & $\begin{array}{r}\text { Upper Regime } \\
\mathrm{h}=2\end{array}$ & $\begin{array}{r}\text { Upper Regime } \\
\mathrm{h}=4\end{array}$ \\
\hline $\mathrm{NE}$ & 0.0073 & 0.0135 & -0.0042 & 0.0079 & -0.0231 & -0.0058 \\
\hline NW & -0.0252 & -0.0053 & -0.0116 & 0.0083 & -0.0040 & 0.0002 \\
\hline$Y \& H$ & 0.0337 & 0.0224 & 0.0393 & 0.0230 & 0.0379 & 0.0261 \\
\hline EM & 0.0129 & 0.0109 & 0.0161 & 0.0118 & 0.0111 & -0.0034 \\
\hline WM & -0.0330 & -0.0333 & -0.0415 & -0.0427 & -0.0436 & -0.0444 \\
\hline East & -0.0178 & -0.0212 & -0.0244 & -0.0318 & -0.0267 & -0.0380 \\
\hline London & 0.0158 & 0.0303 & -0.0006 & 0.0089 & -0.0005 & 0.0115 \\
\hline $\mathrm{SE}$ & 0.0165 & -0.0119 & 0.0622 & 0.0372 & 0.0786 & 0.0682 \\
\hline SW & -0.0281 & -0.0093 & -0.0606 & -0.0433 & -0.0486 & -0.0317 \\
\hline Wales & 0.0082 & 0.0059 & -0.0019 & 0.0118 & 0.0036 & 0.0139 \\
\hline Scotland & 0.0097 & -0.0021 & 0.0272 & 0.0087 & 0.0154 & 0.0036 \\
\hline
\end{tabular}

Table 9: Net Spillover From Each Regional Outflows To Inflows Of All Regions

\begin{tabular}{lrrrrrr}
\hline \hline \multirow{2}{*}{ Region } & $\begin{array}{r}\text { Lower Regime } \\
\mathrm{h}=2\end{array}$ & $\begin{array}{r}\text { Lower Regime } \\
\mathrm{h}=4\end{array}$ & $\begin{array}{r}\text { Middle Regime } \\
\mathrm{h}=2\end{array}$ & $\begin{array}{r}\text { Middle Regime } \\
\mathrm{h}=4\end{array}$ & $\begin{array}{r}\text { Upper Regime } \\
\mathrm{h}=2\end{array}$ & $\begin{array}{r}\text { Upper Regime } \\
\mathrm{h}=4\end{array}$ \\
\hline NE & 0.0807 & 0.0911 & 0.0484 & 0.0668 & -0.0051 & 0.0028 \\
NW & 0.0818 & 0.0701 & 0.1090 & 0.0747 & 0.0730 & 0.0212 \\
Y \& H & -0.0183 & 0.0203 & 0.0132 & 0.0376 & 0.0473 & 0.0354 \\
EM & -0.0442 & -0.0280 & -0.0671 & -0.0389 & -0.0580 & -0.0245 \\
WM & -0.0502 & -0.0477 & -0.0475 & -0.0497 & -0.0540 & -0.0460 \\
East & -0.0215 & -0.0174 & -0.0272 & -0.0192 & -0.0402 & -0.0318 \\
London & -0.0195 & 0.0189 & -0.0132 & 0.0215 & -0.0099 & 0.0099 \\
SE & -0.0391 & -0.0221 & -0.0059 & -0.0096 & 0.0575 & 0.0327 \\
SW & -0.0190 & -0.0030 & -0.0326 & -0.0163 & -0.0424 & -0.0320 \\
Wales & -0.0240 & -0.0108 & -0.0335 & -0.0153 & -0.0162 & -0.0151 \\
Scotland & -0.0038 & -0.0019 & 0.0168 & 0.0088 & 0.0060 & -0.0011 \\
\hline
\end{tabular}

Table 10: Net Spillover From Each Regional Outflows To Vacancies Of All Regions

\begin{tabular}{lrrrrrr}
\hline \hline \multirow{2}{*}{ Region } & $\begin{array}{r}\text { Lower Regime } \\
\mathrm{h}=2\end{array}$ & $\begin{array}{r}\text { Lower Regime } \\
\mathrm{h}=4\end{array}$ & $\begin{array}{r}\text { Middle Regime } \\
\mathrm{h}=2\end{array}$ & $\begin{array}{r}\text { Middle Regime } \\
\mathrm{h}=4\end{array}$ & $\begin{array}{r}\text { Upper Regime } \\
\mathrm{h}=2\end{array}$ & $\begin{array}{r}\text { Upper Regime } \\
\mathrm{h}=4\end{array}$ \\
\hline NE & 0.0193 & 0.0364 & 0.0260 & 0.0514 & 0.0017 & 0.0237 \\
NW & 0.0312 & 0.0419 & 0.0332 & 0.0655 & 0.0045 & 0.0378 \\
Y \& & 0.0285 & 0.0406 & 0.0394 & 0.0599 & 0.0526 & 0.0729 \\
EM & 0.0303 & 0.0347 & 0.0312 & 0.0299 & 0.0177 & 0.0103 \\
WM & 0.0032 & 0.0060 & 0.0091 & 0.0179 & -0.0025 & -0.0017 \\
East & 0.0003 & 0.0138 & 0.0028 & 0.0254 & -0.0115 & 0.0061 \\
London & 0.1090 & 0.0922 & 0.1192 & 0.1156 & 0.0707 & 0.0711 \\
SE & -0.0177 & 0.0117 & 0.0080 & 0.0440 & 0.0404 & 0.0742 \\
SW & 0.0752 & 0.0632 & 0.0540 & 0.0482 & 0.0181 & 0.0145 \\
Wales & -0.0030 & 0.0173 & -0.0257 & 0.0046 & -0.0324 & -0.0039 \\
Scotland & 0.0364 & 0.0498 & 0.0379 & 0.0647 & 0.0122 & 0.0364 \\
\hline
\end{tabular}


East, Wales and Scotland are always net givers in terms of vacancies to vacancies, while Yorkshire and Humberside, London, South East and South West are always receivers. Table 12 implies that, in general, shocks to vacancies tend to decrease the volatilities in inflows. Note that most of the figures in this table have negative values. Especially, shocks to London's vacancy rate tend to decrease the volatilities in inflow rates to around $10 \%$ under all regimes. High propensities to migrate to London may play a part in this. Table 13 shows that shocks to vacancies tend to have negative impact on the variations in outflows.

Table 11: Net Spillover From Each Regional Vacancies To Vacancies Of All Other Regions

\begin{tabular}{lrrrrrr}
\hline \hline Region & $\begin{array}{r}\text { Lower Regime } \\
\mathrm{h}=2\end{array}$ & $\begin{array}{r}\text { Lower Regime } \\
\mathrm{h}=4\end{array}$ & $\begin{array}{r}\text { Middle Regime } \\
\mathrm{h}=2\end{array}$ & $\begin{array}{r}\text { Middle Regime } \\
\mathrm{h}=4\end{array}$ & $\begin{array}{r}\text { Upper Regime } \\
\mathrm{h}=2\end{array}$ & $\begin{array}{r}\text { Upper Regime } \\
\mathrm{h}=4\end{array}$ \\
\hline $\mathrm{NE}$ & -0.0116 & -0.0335 & 0.0253 & -0.0197 & 0.0283 & -0.0090 \\
NW & 0.0269 & 0.0208 & 0.0101 & -0.0010 & -0.0201 & -0.0239 \\
Y \& & -0.0365 & -0.0229 & -0.0343 & -0.0219 & -0.0163 & -0.0009 \\
EM & 0.0207 & 0.0334 & 0.0333 & 0.0335 & 0.0362 & 0.0344 \\
WM & -0.0399 & -0.0342 & -0.0171 & -0.0098 & 0.0097 & 0.0075 \\
East & 0.0303 & 0.0301 & 0.0272 & 0.0333 & 0.0480 & -0.0447 \\
London & -0.0484 & -0.0310 & -0.0718 & -0.0432 & -0.0777 & -0.0573 \\
SE & -0.0332 & -0.0255 & -0.0324 & -0.0072 & -0.0226 & -0.0042 \\
SW & -0.0170 & -0.0117 & -0.0340 & -0.0214 & -0.0391 & -0.0263 \\
Wales & 0.0440 & 0.0336 & 0.0403 & 0.0289 & 0.0312 & 0.0283 \\
Scotland & 0.0647 & 0.0408 & 0.0533 & 0.0286 & 0.0223 & 0.0066 \\
\hline \hline
\end{tabular}

Table 12: Net Spillover From Each Regional Vacancies To Inflows Of All Regions

\begin{tabular}{|c|c|c|c|c|c|c|}
\hline Region & $\begin{array}{r}\text { Lower Regime } \\
\mathrm{h}=2\end{array}$ & $\begin{array}{r}\text { Lower Regime } \\
\mathrm{h}=4\end{array}$ & $\begin{array}{r}\text { Middle Regime } \\
\mathrm{h}=2\end{array}$ & $\begin{array}{r}\text { Middle Regime } \\
\mathrm{h}=4\end{array}$ & $\begin{array}{r}\text { Upper Regime } \\
\mathrm{h}=2\end{array}$ & $\begin{array}{r}\text { Upper Regime } \\
\mathrm{h}=4\end{array}$ \\
\hline $\mathrm{NE}$ & -0.0576 & -0.0753 & -0.0404 & -0.0486 & -0.0244 & -0.0232 \\
\hline NW & 0.0118 & 0.0063 & -0.0501 & -0.0690 & -0.0754 & -0.0729 \\
\hline$Y \& H$ & -0.0106 & -0.0366 & -0.0193 & -0.0399 & -0.0085 & -0.0268 \\
\hline EM & -0.0046 & -0.0198 & 0.0144 & -0.0022 & 0.0162 & 0.0195 \\
\hline WM & -0.0589 & -0.0680 & -0.0763 & -0.0575 & -0.0652 & -0.0178 \\
\hline East & 0.0095 & -0.0114 & 0.0365 & 0.0017 & 0.0438 & 0.0175 \\
\hline London & -0.0816 & -0.0865 & -0.0984 & -0.1047 & -0.0862 & -0.0937 \\
\hline $\mathrm{SE}$ & -0.0498 & -0.0473 & -0.0758 & -0.0494 & -0.0853 & -0.0408 \\
\hline SW & -0.0509 & -0.0492 & -0.0480 & -0.0684 & -0.0434 & -0.0760 \\
\hline Wales & -0.0380 & -0.0286 & 0.0283 & -0.0205 & 0.0632 & -0.0117 \\
\hline Scotland & 0.0095 & -0.0028 & 0.0336 & 0.0036 & 0.0186 & -0.0067 \\
\hline
\end{tabular}

To summarise, six important features leap out from Tables 6-13. First, 
Table 13: Net Spillover From Each Regional Vacancies To Outflows Of All Regions

\begin{tabular}{lrrrrrr}
\hline \hline \multirow{2}{*}{ Region } & $\begin{array}{r}\text { Lower Regime } \\
\mathrm{h}=2\end{array}$ & $\begin{array}{r}\text { Lower Regime } \\
\mathrm{h}=4\end{array}$ & $\begin{array}{r}\text { Middle Regime } \\
\mathrm{h}=2\end{array}$ & $\begin{array}{r}\text { Middle Regime } \\
\mathrm{h}=4\end{array}$ & $\begin{array}{r}\text { Upper Regime } \\
\mathrm{h}=2\end{array}$ & $\begin{array}{r}\text { Upper Regime } \\
\mathrm{h}=4\end{array}$ \\
\hline NE & -0.0669 & -0.0741 & -0.0708 & -0.0768 & -0.0518 & -0.0439 \\
NW & -0.0312 & -0.0175 & -0.0569 & -0.0637 & -0.0467 & -0.0699 \\
Y \& & -0.0393 & -0.0411 & -0.0223 & -0.0287 & 0.0096 & -0.0054 \\
EM & -0.0309 & -0.0211 & -0.0115 & -0.0362 & 0.0160 & -0.0181 \\
WM & -0.0328 & -0.0352 & 0.0055 & -0.0106 & 0.0243 & 0.0088 \\
East & -0.0300 & -0.0330 & -0.0155 & -0.0337 & 0.0309 & -0.0126 \\
London & -0.0173 & -0.0505 & -0.0521 & -0.1018 & -0.0552 & -0.0979 \\
SE & -0.0192 & -0.0446 & -0.0192 & -0.0579 & -0.0213 & -0.0628 \\
SW & -0.0548 & -0.0582 & -0.0758 & -0.0607 & -0.0626 & -0.0560 \\
Wales & 0.0393 & -0.0009 & 0.0445 & -0.0165 & 0.0331 & 0.0000 \\
Scotland & -0.0296 & -0.0314 & -0.0609 & -0.0405 & -0.0478 & -0.0089 \\
\hline \hline
\end{tabular}

outflows from London show that this region is the most important volatility 'giver' affecting vacancies. Its importance in this respect is reduced somewhat in the upper regime (when the economy fares relatively well), suggesting that the capital's role as the engine of the UK economy is particularly important during tough macroeconomic times. Second, outflows tend to have a bigger impact on vacancies than inflows, yet inflows tend to have a bigger impact on outflows than vice versa. This provides further evidence that the interlinkages between the three types of variables are rather complicated. Third, our results corroborate Robson's (2001) finding that vacancies play a minor role in accounting for the variations in outflows. Fourth, if we look at $h=4$, we find that in the lower regime, where the economy is in recession, the net spillovers from inflow to outflow outweigh those from the outflow to inflow, whereas at the middle and upper regime, when the economy is doing better, the net spillovers from outflow to inflow outweigh those from the inflow to outflow. In the literature, there is ongoing debate on whether job separation plays a more important role during recessions (Shimer, 2007; Campolieti, 2011; Elsby et al., 2009). Our empirical 
analysis is not directly designed to address this issue as we do not focus on the first moments as most of these other papers do. However, our results do demonstrate that if we take the UK regional scenario as a whole, there is evidence that in recessions, the variations in job separation rate increase the variations in job finding rate, while when the economy is in better shape, the volatility spillovers take the opposite direction. Fifth, there is clear evidence that under all three regimes, the spillovers from outflow to vacancy rates are bigger than those from inflow to vacancy rates. Finally, we find that compared with regions in England, Wales and Scotland exhibit higher levels of net spillovers from inflows to other variables under all regimes.

In Tables 14-16 we report, for the lower, middle and higher regimes respectively, the net spillovers between the inflow, outflow and vacancy rate within each region. These being net values, the numbers are again small. There appears to be a pattern in which vacancy rate are 'receivers' in most regions. The evidence on the inflow and outflow rates is more mixed. London and the South East again appear as major net 'givers' in terms of outflows, with Wales consistently being a 'receiver'. The opposite is true of inflows.

\section{Conclusion}

This paper proposes a smooth-transition VAR model of high dimension to investigate the intra- and inter- regional linkages between the job separation rate, job finding rate and vacancies. Our model is an extension of the standard multivariate matching model explored in Fujita (2011) and Campolieti et al. (2014a). Using DAELasso of Gefang (2014) and GSM of Diebold 
Table 14: Net Spillovers Within Regions, Lower Regime

\begin{tabular}{llrrr}
\hline \hline & Region & Inflow Rate & Outflow Rate & Vacancy Rate \\
\hline NE & 0.0050 & 0.0033 & -0.0083 \\
NW & 0.0040 & 0.0109 & -0.0149 \\
Y \& H & -0.0049 & 0.0155 & -0.0106 \\
EM & -0.0023 & 0.0122 & -0.0098 \\
WM & -0.0060 & -0.0053 & 0.0113 \\
$h=2$ & East & 0.0536 & -0.0356 & -0.0180 \\
London & 0.0023 & -0.0060 & 0.0037 \\
SE & 0.0216 & -0.0005 & -0.0211 \\
SW & 0.0041 & 0.0037 & -0.0078 \\
Wales & 0.0277 & -0.0486 & 0.0209 \\
Scotland & 0.0140 & -0.0088 & -0.0052 \\
\hline NE & 0.0002 & 0.0127 & -0.0129 \\
NW & -0.0020 & 0.0089 & -0.0069 \\
Y \& H & -0.0039 & 0.0096 & -0.0057 \\
EM & -0.0009 & 0.0038 & -0.0029 \\
WM & -0.0027 & 0.0022 & 0.0005 \\
East & 0.0274 & -0.0180 & -0.0094 \\
London & -0.0053 & 0.0129 & -0.0076 \\
SE & 0.0075 & 0.0065 & -0.0140 \\
SW & 0.0004 & 0.0050 & -0.0054 \\
Wales & 0.0218 & -0.0265 & 0.0047 \\
Scotland & 0.0098 & -0.0055 & -0.0043 \\
\hline \hline
\end{tabular}


Table 15: Net Spillovers Within Regions, Middle Regime

\begin{tabular}{llrr}
\hline \hline Region & Inflow Rate & Outflow Rate & Vacancy Rate \\
\hline NE & -0.0043 & 0.0010 & 0.0033 \\
NW & 0.0099 & 0.0213 & -0.0312 \\
Y \& H & -0.0102 & 0.0328 & -0.0226 \\
EM & -0.0032 & 0.0149 & -0.0117 \\
$h=2$ & -0.0086 & -0.0067 & 0.0153 \\
WM & 0.0412 & -0.0230 & -0.0183 \\
East & 0.0015 & 0.0045 & -0.0059 \\
London & 0.0112 & 0.0236 & -0.0348 \\
SE & 0.0011 & 0.0036 & -0.0047 \\
SW & 0.0125 & -0.0582 & 0.0457 \\
Wales & 0.0105 & -0.0018 & -0.0087 \\
Scotland & -0.0063 & 0.0062 & 0.0002 \\
NE & 0.0023 & 0.0201 & -0.0224 \\
NW & -0.0033 & 0.0107 & -0.0073 \\
Y \& H & -0.0013 & 0.0071 & -0.0058 \\
EM & -0.0029 & -0.0050 & 0.0079 \\
WM & 0.0184 & -0.0071 & -0.0113 \\
East & -0.0014 & 0.0190 & -0.0176 \\
London & 0.0025 & 0.0190 & -0.0216 \\
SE & 0.0027 & 0.0034 & -0.0061 \\
SW & 0.0218 & -0.0300 & 0.0082 \\
Wales & 0.0027 & 0.0043 & -0.0071 \\
Scotland & & &
\end{tabular}


Table 16: Net Spillovers Within Regions, Upper Regime

\begin{tabular}{llrr}
\hline \hline Region & Inflow Rate & Outflow Rate & Vacancy Rate \\
\hline NE & -0.0057 & 0.0006 & 0.0051 \\
NW & 0.0104 & 0.0138 & -0.0242 \\
Y \& H & -0.0129 & 0.0352 & -0.0223 \\
EM & -0.0053 & 0.0126 & -0.0073 \\
WM & -0.0036 & -0.0082 & 0.0118 \\
$h=2$ & 0.0168 & -0.0154 & -0.0015 \\
East & -0.0011 & 0.0115 & -0.0104 \\
London & -0.0006 & 0.0336 & -0.0330 \\
SE & 0.0056 & -0.0015 & -0.0041 \\
SW & -0.0009 & -0.0406 & 0.0415 \\
Wales & 0.0060 & 0.0004 & -0.0064 \\
Scotland & -0.0053 & 0.0012 & 0.0042 \\
NE & 0.0055 & 0.0145 & -0.0200 \\
NW & -0.0018 & 0.0078 & -0.0060 \\
Y \& H & -0.0047 & 0.0056 & -0.0009 \\
EM & 0.0023 & -0.0090 & 0.0067 \\
WM & 0.0055 & -0.0068 & 0.0013 \\
East & 0.0034 & 0.0177 & -0.0211 \\
London & 0.0012 & 0.0151 & -0.0163 \\
SE & 0.0105 & -0.0016 & -0.0089 \\
SW & 0.0156 & -0.0197 & 0.0041 \\
Wales & -0.0018 & 0.0040 & -0.0022 \\
\hline Scotland & & & \\
\hline \hline
\end{tabular}


and Yilmaz (2012), we are able to track the dynamic volatility spillover mechanism in $11 \mathrm{UK}$ regions.

Our empirical evidence suggests the existence of close interlinkages between UK regional labour markets, with regime changes driven by confidence. We find that, in general, shocks to job separation rates tend to spread into job finding and vacancy rates. By contrast, vacancy rates are usually at the receiving ends of shocks transmitted from the job separation and finding rates. The impacts of shocks to regional outflow rates are mixed. Yet, there is clear evidence that shocks to outflows play a more important role in affecting the volatilities in vacancy rates than shocks to inflow rates or vacancy rates. These propagation mechanisms all operate somewhat differently across the various regimes - or the state of the business cycle - considered. This last observation has an important policy implication, namely that actions taken to mitigate adverse labour market shocks need to be taken in cognisance of the parameters associated with the regime in which the economy operates after the shock. What works in good times may not work in bad.

Of particular interest in the context of current policy debates is the changing impact of the job market in London on that of other regions. In the lower regime outflows from unemployment in the capital exert a stronger influence on outflow patterns in other regions than is the case in the higher regime. This offers some reassurance that the current recovery, which has started in London and the surrounding region, will (as has happened in the past) have a beneficial impact on labour markets in other regions. Testing that prediction in real time will, of course, require further research. 


\section{References}

[1] Acemoglu, D and A. Scott (1994), Consumer Confidence and Rational Expectations: Are Agents' Beliefs Consistent with the Theory? Economic Journal, 104(422), 1-19.

[2] Akerlof, G. A, A. K. Rose and J. L. Yellen (1988), Job Switching and Job Satisfaction in the U.S. Labor Market, Brookings Papers on Economic Activity, 2, 495582.

[3] Albæk1, K. and H. Hansen (2004), The Rise in Danish Unemployment: Reallocation or Mismatch? Oxford Bulletin of Economics and Statistics, 66(4), 515536,

[4] Altera, A. and A. Beyer (2014), The dynamics of spillover effects during the European sovereign debt turmoil, Journal of Banking and Finance, $42,134153$.

[5] Anderson, P. M. and S. M. Burgess (2000), Empirical Matching Functions: Estimation and Interpretation Using Disaggregate Data, Review of Economics and Statistics, 82(1), 93102.

[6] Antonakakis, N. (2012), Exchange return co-movements and volatility spillovers before and after the introduction of euro, Journal of International Financial Markets, Institutions and Money, 22(5), 1091-1109.

[7] Banbura, M, D. Giannone and L. Reichlin (2010), Large Bayesian vector auto regressions, Journal of Applied Econometrics, 25, 71-92. 
[8] Bennet, Robert J. and Ricardo R. Pinto (1994), The Hiring Function in Local Labour Markets in Britain, Environment and Planning, 26(12), 195774.

[9] Blanchard, O.J. and P.A. Diamond (1989) The Beveridge Curve, Brookings Papers on Economic Activity, 1, 176.

[10] Burgess, S. and S. Profit (2001), Externalities in the matching of workers and firms in Britain, Labour Economics, 8(3), 313333.

[11] Burgess, S. and H. Turon (2005), Unemployment Dynamics in Britain, The Economic Journal, 115, 423448

[12] Campolieti, M. (2011), The ins and outs of unemployment in Canada, 19762008, Canadian Journal of Economics 44(4), 13311349.

[13] Campolieti, M., D. Gefang and G. Koop (2014a), Time Variation in the Dynamics of Worker Flows: Evidence from North America and Europe, Journal of Applied Econometrics, 29, 265-290.

[14] Campolieti, M., D. Gefang and G. Koop (2014b), A New Look at Variation in Employment Growth in Canada: The Role of Industry, Provincial, National and External Factors, Journal of Economic Dynamics and Control, 41, 257-275.

[15] Canova, F., D. Lopez-Salido and C. Michelacci (2013), The Ins and Outs of Unemployment: An Analysis Conditional on Technology Shocks, Economic Journal, 123(569), 515-539. 
[16] Coles, M. G. and E. Smith (1996) Cross-Section Estimation of the Matching Function: Evidence from England and Wales, Economica, $63(252), 58998$.

[17] Coles, M.G. and Petrongolo (2013) A Test Between Unemployment Theories Using matching Data, CEP DP570.

[18] Corrado, L., Martin, R. and Weeks, M. (2005) Identifying and interpreting regional convergence clusters across Europe, Economic Journal, 115, C133-C160.

[19] Crone, T.M. (2006) What a new set of indexed tells us about state and national business cycles, Federal Reserve Bank of Philadelphia Business Review, 1, 11-24.

[20] Crouch, C. (2012), Beyond the Flexibility/Security Trade-Off: Reconciling Confident Consumers with Insecure Workers, British Journal of Industrial Relations, 50(1), 122.

[21] Diamond, P. A. (1982), Wage Determination and Efficiency in Search Equilibrium, Review of Economic Studies, 49(2): 21727.

[22] Diebold, F. and K. Yilmaz (2012), Better to give than to receive: Predictive directional measurement of volatility spillovers, International Journal of Forecasting, 28, 57-66.

[23] Doan, T., R. Litterman and C. Sims (1984), Forecasting and conditional projections using realistic prior distributions, Econometric Reviews, 3, $1-100$. 
[24] Duranton, G. and V. Monastiriotis (2002) Mind the gaps: the evolution of regional inequalities in the UK 1982-1997, Journal of Regional Science, 42, 219-256.

[25] Elsby, M., R. Michaels and G. Solon (2009), The ins and outs of cyclical unemployment, American Economic Journal: Macroeconomics, 1, 84110.

[26] Evans, P. and B. McCormick (1994) The new pattern of regional unemployment: causes and policy significance, Economic Journal, 104, 633-647.

[27] Fujita, S. (2011). "Dynamics of worker flows and vacancies: Evidence from the sign restriction approach," Journal of Applied Econometrics, $26,89-121$.

[28] Gefang, D. (2014), Bayesian Doubly Adaptive Elastic-Net Lasso for VAR Shrinkage, International Journal of Forecasting, 30(1), 1-11.

[29] Gefang, D. and R. Strachan (2010), Nonlinear Impacts of International Business Cycles on the UK A Bayesian LSTVAR Approach, Studies in Nonlinear Dynamics \& Econometrics, 14(1), 2.

[30] Geman, S. and D. Geman (1984), Stochastic Relaxation, Gibbs Distributions, and the Bayesian Restoration of Images, IEEE Transactions on Pattern Analysis and Machine Intelligence 6(6), 721741

[31] George, E., D. Sun and S. Ni (2008), Bayesian stochastic search for VAR model restrictions, Journal of Econometrics, 142, 553-80. 
[32] Hämäläinen, K and P. Böckerman (2004) Regional Labor Market Dynamics, Housing and Migration, Journal of Regional Science, 44, 543568.

[33] Hatton, T. J. and M. Tani (2005), Immigration and Inter-Regional Mobility in the UK, 1982-2000, Economic Journal, 115(507), 342-358.

[34] Hubrich, K. and T. Teräsvirta. (2013), "Thresholds and Smooth Transitions in Vector Autoregressive Models," CREATES Research Papers 2013-18, School of Economics and Management, University of Aarhus.

[35] Johnes, G. and T.J. Hyclak (1999) House Prices and Regional Labor Markets, Annals of Regional Science, 33, 33-49.

[36] Kadiyala, K.R. and S. Karlsson (1997), Numerical methods for estimation and inference in Bayesian VAR-models, Journal of Applied Econometrics, 12(2), 99-132.

[37] Kass, R.E. and A.E. Raftery (1995), Bayes Factors, Journal of the American Statistical Association, 90, 773-795.

[38] Koop, G. (2011), Forecasting with medium and large Bayesian VARs, Journal of Applied Econometrics, doi: 10.1002/jae.1270.

[39] Kose, M.A., C. Otrok and C. Whiteman (2003), International Business Cycles: World, Region and Country-Specific Factors. American Economic Review, 93, 1216-1239. 
[40] Litterman, R.(1986), Forecasting with Bayesian vector autoregressions five years of experience, Journal of Business and Economics Statistics, $4,25-38$.

[41] Longhi, S. and P. Nijkamp (2007), Forecasting Regional Labor Market Developments under Spatial Autocorrelation, International Regional Science Review, 30(2), 100-119.

[42] Lütkepohl, H. (2007), New Introduction to Multiple Time Series Analysis, Springer.

[43] Machin, A. and V. Christian (2002) A New Survey of Job Vacancies: the First Experimental Results, Labour Market Trends, 110, 535-548, http://www.ons.gov.uk/ons/rel/lms/labour-market-trendsdiscontinued-/volume-110-no-10/a-new-survey-of-job-vacancies-thefirst-experimental-results.pdf.

[44] Maddala, G. S. (1977), Econometrics, McGraw-Hill, New York.

[45] Manning, N. (1994) Earnings, unemployment and contiguity: evidence from British counties 1976-1992, Scottish Journal of Political Economy, 41, 43-68.

[46] Martin, R. (1997) Regional unemployment disparities and their dynamics, Regional Studies, 31, 237-252.

[47] McCormick, B. (1997) Regional unemployment and labour mobility in the UK, European Economic Review, 41, 581-589. 
[48] Owen, D.W. and A.E. Green (1989) Spatial Aspects of Labour Mobility in the 1980s, Geoforum, 20, 107-126.

[49] Petrongolo, B. and C. A. Pissarides (2001), Looking into the Black Box: A Survey of the Matching Function, Journal of Economic Literature, $39(2), 390-431$.

[50] Pissarides, C. A. and J. Wadsworth (1989), Unemployment and the Inter-Regional Mobility of Labour, Economic Journal, 99(397), 739755.

[51] Robson, M. T.(2001), Regional Variations in the Competitiveness of Unemployed Job-seekers and the Rate of Outflows From Unemployment, Oxford Bulletin of Economics and Statistics, 63(1), 6190.

[52] Sensier, M. and M. Artis (2011) Tracking unemployment in Wales through recession and into recovery, available at http://www.spatialeconomics.ac.uk/textonly/SERC/publications/download/sercdp0079.pdf, accessed 9 April 2014.

[53] Shimer, R. (2007), Reassessing the ins and outs of unemployment, $\mathrm{Na}$ tional Bureau of Economic Research, working paper 13421.

[54] Sims, C. (1972), Money, Income and Causality, American Economic Review, 62, 540-52.

[55] Sims, C. (1980), Macroeconomics and Reality, Econometrica, 48, 1-48.

[56] Stock, J. H. and M. W. Watson (1999), Forecasting inflation, Journal of Monetary Economics, 44(2), 293-335. 
[57] Taylor, J. and S. Bradley (1994) Spatial disparities in the impact of the 1990-1992 recession: an analysis of UK counties, Oxford Bulletin of Economics and Statistics, 56, 367-382.

[58] Teräsvirta, T. (1994) Specification, estimation, and evaluation of smooth transition autoregressive models, Journal of the American Statistical Association, 89, 208-218.

[59] Tong, H. (1983). Threshold Models in Non-linear Time Series Analysis, Springer-Verlag, New York.

[60] Townsend, A. and T. Champion (2014) The impact of recession on city regions: the British experience, 2008-2013, Local Economy, 29, 38-51.

[61] Wasserman, L. (2000), Bayesian Model Selection and Model Averaging, Journal of Mathematical Psychology, 44, 92-107. 